Herrn Hofrat Prof. Dr. Viktor Ritter $\nabla 0$ n Ebner anlässlich seines Jubellehrjahres gewidmet von seinem ältesten seinerzeitigen Assistenten.

\title{
Über die Trichopoden und Granula aestuantia der menschlichen Leukozyten.
}

\author{
Von \\ Prof. Dr. Ludwig Merk, \\ Vorstand der dermatologischen Klinik Innsbruck.*) \\ Hierzu Tafel XXV.
}

Bekanntlich zeigen menschliche Leukozyten aus frischem Eiter oder im nativen Blutpräparat bei Dunkelfeldbeleuchtung histologische Eigentümlichkeiten von solcher Besonderheit ${ }^{1}$ ), dass derjenige, der solche überlebende weisse Blutkörperchen nur einmal im Dunkelfeld beobachtet hat, kaum mehr darnach verlangt, sie im durchfallenden Lichte oder im gefärbten Zustande zu untersuchen. Die eine Besonderheit besteht darin, dass die neutrophilen Granula, wohl aber auch die basophilen Granula den Körper der Leukozyten in Form von ausserordentlich hell glänzenden Kügelchen erfüllen, die sich lebhaftest ähnlich bewegen, wie die Luftblasen im Gischt eines Wasserfalles ${ }^{2}$ ). Ich werde für sie im folgenden den Namen Granula aestuantia in Anwendung bringen. Sie sind hellweiss, unter Umständen gelb. An denselben Zellen sind sie und ihre Bewegung im durchfallenden Lichte nicht wahrzunehmen. Ebenso kann man sie an dem angetrockneten, fixierten, gefürbten Prăparate vermissen, namentlich wenn man nicht besonders flink war.

1) Vergleiche: Wiener klinische Wochenschrift 1907, Nr. 31. Sitzungsbericht der wissenschaftlichen Ärztegesellschaft in Innsbruck vom 19. Jänner 1907 und

V. Schilling, Lebende weisse Blutkörperchen im Dunkelfeld. Folia hämatologica. VI. Bd. 1908. S. $429 \mathrm{ff}$.

Derselbe, Berliner. Hämatologische Gesellschaft. Sitzungsbericht. Folia hämatologica. IX. Bd. S. $170 \mathrm{ff}$.

$\left.{ }^{2}\right)$ Aestus ist nach freundlicher Mitteilung des klassischen Philologen unserer Universität, Herrn Prof. Dr. Ernst $\mathrm{K}$ a linka der beste lateinische Ausdruck für Gischt.

*) Die Assistenten und Schüler des Herrn Hofrat von Ebner geben aus Anlass des Jubellehrjahres keine Festschrift heraus, sondern publizieren ihre Widmungen an beliebigem Orte. Die Sammlung der Sonderabdrücke wird dem Jubilar als Festband überreicht.

Archiv 1. mikr. Anat. Bd. 80. Abt. I. 
Die $\mathrm{zw}$ wite Besonderheit besteht darin, dass an den lebenden Leukozyten oft erstaunlich lange, ausserst feine Fortsätze auftauchen, denen man den Namen von Trichopoden geben kann und die zuweilen büschelartig von einem Zellteile in die Umgebung hinausstrablen.

Ich habe es mir im folgenden zur Aufgabe gestellt, die beiden Phănomene einer experimentellen Prüfung zu unterziehen. Die beiden Erscheinungen sind voneinander unabhängig. Ich könnte sie also getrennt besprechen. Beide aber erlöschen mit dem Tode der Zellen, laufen sohin an der lebenden Zelle nebeneinander, so dass sie in den Beobachtungsprotokollen immer gleichzeitig berücksichtigt werden mussten.

Ich erlaube aber aufmerksam zu machen, dass die zu verwendende Lichtquelle nicht stark genug sein kann. Ich benütze eine Wechselstrombogenlampe der Firma $\mathrm{K}$ örtin \& $\mathrm{M}$ a th i es e mit automatischer Regulierung. Die senkrecht übereinanderstehenden Dochtkohlenstifte haben $12 \mathrm{~mm}$ Durchmesser und $150 \mathrm{~mm}$ Lange. Die Lichtbogenspannung der Lampe betragt ungefabr 35 Volt, die Stromaufnahme ungefihr 12 Ampère, die mittlere răumliche Lichtstärke schatzungsweise 400 Normalkerzen. Die Netzspannung von 120 Volt wird mittels Transformator auf 60 Volt transformiert, an welche Spannung die Lampe mit ihrem Vorschalt- oder Beruhigungswiderstand angeschlossen ist, welcher 25 Volt (60 minus 35 Volt) vernichtet. Die Distanz der Kohlenenden betrug wenige Millimeter. Die Distanz der Lichtquelle vom Spiegel des Mikroskopes betrug $60 \mathrm{~cm}$. Die Lichtstrahlen wurden mit einer Sammellinse auf den Spiegel konzentriert und von dort in den von der Firma $R$ eichert gelieferten Kondensor $B$ reflektiert. Von einer Warmewirkung kann nicht die Rede sein, denn der Brennpunkt der konzentrierten unreflektierten Strahlen brachte ein Thermometer innerbalb von fünf Minuten allmăhlich auf $32^{\circ} \mathrm{C}$. In zwölf Minuten stieg es weiter auf $34,5^{\circ}$ und fiel bis zur 21. Minute auf $32^{\circ}$. In den Kondensor dringen aber kăltere, reflektierte Strahlen, denen ausserdem im Weiterverlaufe ins Prăparat weitere Wärmemengen entzogen werden. Zur Verschiebung des Präparates diente ein beweglicher Objekttisch. Sämtliche Beobachtungen wurden mit dem ganz vorzüglichen Objektive Nr. 9 der Firma R eich er t ausgeführt. Als Okular diente zumeist Kompensationsokular Nr. 4 derselben Firma. Zu Messungen Nr. 6. 
Zum Teil untersuchte ich die Objekte ohne irgendwelche Zusatzflüssigkeit. Zum grösseren Teile mengte ich sie, und zwar in diesem Falle durchgängig Eiter, mit Kochsalzlösungen, Traubenzuckerlösungen verschiedener Konzentration oder mit Flüssigkeiten, von denen noch weiter die Rede sein soll. Den Eiter nahm ich zumeist frisch aus der Harnröhre von Gonorrhoikern. Man kann aber ebensogut irgendwelchen Eiter, nur muss er frisch und lebenswarm sein, zur Untersuchung heranziehen. Nachuntersuchern möchte ich vorschlagen, zunächst Eiter mit 0,8 proz. Chlornatriumlösung $z u$ vermengen und $z$ war möglichst wenig Eiter zu je einem Präparat. Von den einzelnen Beobachtungen sammelte ich Protokolle, die ich zum Teil diktierte, wăhrend ich die Beobachtung ausführte, zum Teil musste ich das Protokoll selbst niederschreiben. Letzteres hat seine Nachteile, weil wäbrend der Niederschrift Veränderungen auftreten können, deren Zusammenhang leicht verloren geht. Das Gleiche gilt für die Zeichnungen. Ich hatte nie Zeit, diesen grössere Sorgfalt zukommen zu lassen, weshalb dieselben eigentlich nur als Skizzen gelten mögen.

Die im folgenden mitgeteilten Beobachtungsprotokolle stellen nur eine Auswabl der markantesten vor. Bezüglich ibrer Fassung sei folgendes bemerkt. Sobald das Präparat fertiggestellt war, setzte ich eine Minutenstoppuhr in Gang. Ich notierte dann die Zeit der Registrierung im Protoliolle. Es bedeuten sohin beispielsweise die Zahlen 1,$30 ; 34 ; 34,45$ etc., dass bis zum Diktate oder zur Niederschrift der betreffenden Notiz eine Minute 30 Sekunden, 34 Minuten, 34 Minuten 45 Sekunden seit Herstellung des Prïparates verstrichen waren. Ftwaige Febler wären nach Sekunden zu abzuschätzen.

\section{A. Versuche mit Kochsalzlösungen.}

Einem Tropfen leicht gewärmter 0,75 proz. Kochsalzlösung wird eine Spur frischen gonorrhoischen Eiters zugesetzt und das Ganze mit einem Deckglas bedeckt. 1,30, die Leukozyten sind kugelig. Sie scheinen kaum etwas grösser als Erythrozyten zu sein. Die Kerne sind kaum sichtbar. Sie schwimmen, getragen von der Strömung im frischen Präparate hin und wieder. 2,35, die Kerne werden als dunkle Lücken sichtbar. Die Zellen legen sich allmählich an den Objektträger, weniger an das Deckglas, 
werden flach und erscheinen dadurch jetzt fast doppelt so gross. Das Plasma selbst ist unsichtbar. Die Grenzen der Pseudopodien und ibre Änderung während des Vorstreckens erkennt man zum Teil an einem schmalen Glanz der Umsäumung, zum Teil daran, dass der glänzende Inbalt der Leukozyten sich in das Plasma der Pseudopodien ergiesst. Der Körnergischt, der schon an den flottierenden Fiterkörperchen bestanden hatte, ist jetzt klarer zu sehen, insbesondere heben sich die einzelnen Granula deutlich ab. Sie stürzen in die vorgestreckten Pseudopodien sprudelnd nach.

Gleichzeitig mit diesem Prïparate hatte ich ein ganz analoges angefertigt. Ich brachte es bei derselben Vergrösserung an einem anderen Mikroskope in durchfallendes Licht. Von dem Gischt war nichts zu sehen. Im Plasma der Leukozyten wogte es langsam hin und her, âhnlich den sich rasch ändernden Wolken. Es tauchen wohl $a b$ und $z u$ in den weiterkriechenden Eiterzellen Körnchen auf, aber sehr träge und man muss scharf und lange zusehen, wenn man ihr Erscheinen und Verschwinden bemerken will.

Man kann auch dasselbe Prilparat, das man im Dunkelfeld beobachtet, und dieselben Zellen, an denen man den Gischt so lebhaft vorfand, im durchfallenden Licht beobachten, wenn man den Kondensor ausschaltet und die starke Lichtquelle etwa durch Vorhalten eines Seidenpapierschirmes verringert. Auch dann ist von dem Gischt an ebendenselben Zellen nichts anderes wahrzunehmen, als was ich eben andeutete und was ohnehin jedem Histologen geliufig ist.

Neine Absicht war, an dem Präparate das Auftreten der Trichopoden in der Skizze festhalten zu können. Allein die Leukozyten, die ich zu diesem Zwecke im Auge behielt, trieben leider nicht zu dieser Veränderung.

10 z. B. fasste ich einen Leukozyten ins Auge (siebe Fig. 1). Der Umriss der Zelle war rundlich mit einer flachen Spitze nach obenhin. Der Kern erschien in Form von vier dunklen Lücken und der ganze übrige Raum der Zelle war vom Gischt erfüllt. 12,30 hatte sich die Kernmasse verlagert (siehe Fig. 1 b) und am oberen Teil der Zelle ist ein dunkler Raum entstanden, in welchen die Sprudelkörner alsbald hineinstürzen. 15; die dunklen Lücken der Kernmasse haben sich mittlerweile 
wieder geăndert. Die Zelle zeigt nach oben und unten Pseudopodien (Fig. 1 c), die aber immer vom Sprudelgischt erfüllt bleiben. 17 ist der Fuss nach unten langer geworden und die Zelle selbst flacher, grösser. Die Kernmasse besteht aus drei Teilen, dazwischen der weisse Sprudelgischt (Fig. 1d). Obschon zur gleichen Zeit andere Leukozyten des Präparates Trichopoden angebildet hatten, ist an dieser speziell beobachteten Zelle nichts davon zu sehen. 22 musste ich die Beobachtung dieser Zelle aufgeben.

28 skizzierte ich (Fig. 2) einen Leukozyten mit einem Büschel von Trichopoden an einem Ende. Der Gischt lag in kompakter, abgeschlossener Masse im Innern der Zelle. Ibm links oben angelagert der Kern. Beide Gebilde umschloss mit breitem Saume die übrige, schwach leuchtende Masse des Leukozyten und nach links strahlte ein Trichopodenbüschel, bestehend aus sechs bis sieben Fäden, von denen einige verzweigt waren.

31 fand ich einen weiteren Leukozyten (siehe Fig. 3) mit dem Gischt in der Mitte. Der Kern war unsichtbar und offenbar durch die Körnermasse verdeckt. Mit unregelmässig gestaltetem Hofe umgab die Masse der Zelle den Gischt und vom oberen Ende strahlte ein Trichopodenbüschel aus, bestehend aus bellweissen Fäden, von denen einige an den Enden Verzweigungen trugen.

34 bot mir ein anderes Eiterkörperchen Gelegenheit, die Trichopodenbildung zu studieren. Die betreffende Zelle (siehe Fig. 4) zeigte inmitten des Gischtes vier ziemlich regelmässig verteilte Kernmassen. Um den Gischt befand sich ein verschieden breiter Plasmasaum, von welchem 34 nach links oben ein Faden ausstrahlte, der schätzungsweise fünfmal so lang war, als der scheinbare Durchmesser der Zelle. Wahbrend ich die Zelle skizzierte, knickte der Faden ungefähr in der Mitte ein, etwa wie ein gerader Stab einbricht. In diesem Zustande flottierte er eine kleine Weile und verschwand plötzlich in der Masse der Zelle. Ich wollte mich schon einem anderen weissen Blutkörperchen zuwenden, als ebenso plötzlich rechts oben zwei weisse Fäden auftauchten. In denselben lohte das Licht stellenweise auf und $\mathrm{ab}$; es entstanden hellere bazillenlange Verdickungen, die bald da bald dort aufleuchteten.

40 dringt vielfach Luft in das Präparat und ich gebe die Weiterbeobachtung auf. 
Wer diese sonderbaren Erscheinungen das erstemal sieht, könnte meinen, dass das enorme Licht ihr Auftreten verursacht oder begünstigt. Deshalb hatte ich mehrere Male Parallelpräparate hergestellt, von denen je eines im Dunkeln liegen blieb. Wenn ich dann im Dunkelfelde die beschriebenen Veränderungen gesehen hatte, schaltete ich das Parallelpräparat ein und konnte mich jedesmal überzeugen, dass die gleichen Veränderungen an dem aufbewahrten Präparate mittlerweile auch aufgetreten waren.

Ich liess das mit dem Deckglas bedeckte Praparat eintrocknen und träufelte den năchsten Tag neuerdings Kochsalzlösung zu. Dann war von Trichopoden nichts mehr zu sehen. Die Gestalt und das Aussehen der Zellen bot nichts Ungewöhnliches. Der Zellkern liegt wie ein dunkles Loch im Leukozyten. Die Masse desselben ist fein krümelig, stellenweise von weisser Farbe. Granula fehlen und der Gischt ist selbstredend schon lange erloschen.

Leider weiss ich mir leine Methode auszudenken, den Vorgang des Austrocknens selbst im Dunkelfelde zu verfolgen. Nimmt man einen Eitertropfen und deckt ihn mit einem Deckglase, so ist die Masse der Zellen so dicht, dass man Einzelheiten in geringem Ausmaße verfolgen kann. Man sieht nur allenthalben den Gischt. Ich verfertigte daher Trockenpräparate, wie man dieselben zum Zwecke bakterieller Färbungen anzufertigen pflegt. Also sogenannte Ausstrichpräparate. Es dauert immerhin einige Zeit, manchmal einige Minuten, bis der Eiter völlig trocken ist. Fügt man jetzt einen Tropfen Methylalkohol zu und deckt mit dem Deckglăschen, so erscheinen im Dunkelfelde die Leukozyten von gewöhnlicher Gestalt, zumeist rundlich. Die Kerne sind deutlich als dunkle Flecken. Um sie herum eine leicht wolkige, gräulichweisse Masse. War man sehr langsam und verstrich viel Zeit (mehrere Minuten bis zum Trockenwerden), so ist von Granulis in den Leukozyten nichts zu sehen. Wohl aber finden sich extrazellulär eine Unzahl glänzender Körnchen, die sich durch nachfolgende Färbung als neutrophile Granula entpuppen. Geschah die Antrocknung sehr rasch, so erfüllen noch viele neutrophile Granula die Zelle - im Dunkelfeld ebensogut $z u$ erkennen, wie im gefarbten Präparate. Es genügt also eine ganz kurze Zeit, dass die Granula aestuantia den Zelleib verlassen und ausserhalb desselben sich antrocknen. 
Mit dieser Beobachtung stimmt es daher auch überein, dass die Zahl der neutrophilen Granula in verschiedenen Ausstrich-Trocken-Präparaten derselben Provenienz verschieden gross sein kann.

Inwieweit die basophilen Granula an dieser Expulsion aus der lebenden Zelle beteiligt sind, konnte ich nicht feststellen.

Es schien mir zunächst von Interesse, wie sich die Zellen verschiedenen Konzentrationsgraden gegenüber verhalten würden. Ich begann daher mit Zusätzen von destilliertem Wasser. Dass dasselbe den Zellen sehr nachteilig sein müsse, war von vornherein anzunehmen. 1 bleiben sie eine Weile kugelig und die Strömung im Präparate treibt sie hin und her. Der Sprudelgischt ist ganz besonders lebhaft. Er ist, wie man durch Untersuchung von Parallelpräparaten feststellen kann, nun auch im durchfallenden Lichte gut, wenn auch nicht ganz so deutlich, sichtbar. Etwa 1,30 hat es den Anschein, als ob eine oder die andere Zelle versuchen würde, einen breiten amöboiden Fortsatz auszustrecken. Kaum kommt es aber zur Vorwölbung, so platzt die Zelle und die Granula entströmen unter Einbusse ihrer Sprudelbewegung in das umgebende Wasser. 6 ist kaum mehr eine unversehrte Zelle zu finden. Trichopoden haben sich keine gebildet.

Nun griff ich zu einer starken Konzentration von 3,75 Prozent. 1,55 liegen die Leukozyten als schollige, mehr weniger eckige, hellweiss glänzende Gebilde in der Flüssigkeit, ohne Spur eines Saumes und ohne den geringsten Gischt. Die Kerne sind unsichtbar. 2,35 finde ich an einer Zelle des Gesichtsfeldes einen ungefahr $8 \mu$ langen flottierenden Trichopod. Keine der Zellen haftet fest. 7,15 stosse ich auf eine zweite Zelle mit sehr dünnem Trichopod, 7,50 auf eine weitere. 10 haften die Zellen noch immer nicht am Glase und noch immer fehlt der Gischt. 16,45 finde ich einen Leukozyten mit einem langen Trichopod, dessen freies Ende am Glase fixiert ist (siehe Fig. 5). Der Faden ist links oben fixiert und die von dort nach rechts unten ziehende Strömung lässt den Leukozyten am Faden baumeln. Andere vorbeiströmende Leukozyten legen sich an die fixierte Zelle an, schwenken sie dabei an der Anheftungsstelle hin und her, ohne das ganze Gebilde wegzuschwemmen. 19 sieht man hăufiger weisse Blutkörper mit Trichopoden, als zu Anfang der Beobachtung, wenn 
auch noch spärlich. Die Fadenfortsătze sind aber nicht steif, wie in physiologischer Kochsalzlösung. 21, die verankerte Zelle, die ich 16,45 gefunden hatte, haftet noch immer an derselben Stelle, obschon die Strömung viele andere Leukozyten mitunter recht heftig nach rechts unten getrieben hatte. 22, unter einem Ruck schlagt die Strömung in die entgegengesetzte Richtung. Der Haftfaden entspannt sich, bleibt aber am Glase und so baumelt der Leukozyt eine Weile nach links oben, manchmal bis über die Anheftungsstelle des Fadens hinaus. 24 löste sich der Faden rom Glase und die Zelle schwimmt mitsamt dem Faden in der Richtung der Strömung fort.

28 sehe ich einen Leukozyt (siehe Fig. 6), der das entgegengesetzte Phänomen zeigt: $\mathrm{Er}$ haftet mit einem Pseudopod am Glase, indes vom entgegengesetzten Ende ein Trichopod von etwa $10 \mu$ Länge in der Strömung flottiert. Nach kürzester Zeit aber wird das ganze Gebilde fortgeschwemmt.

30 finde ich abermals einen an einem 'Trichopod verankerten Leukozyten. 31 kommen im Präparate heftige, ruckweise Strömungen zustande. Die Zahl der Zellen mit Trichopoden hat zugenommen. Von manchen strahlen auch Büschel von drei und vier Trichopoden aus. 33 breche ich die Untersuchung ab. Kein Leukozyt ist bisher mit dem ganzen Körper am Glase haften geblieben. Sie waren durchaus schollig geblieben und wurden nie kuchenförmig abgeplattet. Infolgedessen blieben auch ihre Durchmaße verhăltnismässig klein. Kerne kamen nie zur Beobachtung und ein Gischt war nie zu sehen.

Sehr interessant sind die Bilder, die man nach Zusatz von geringen Konzentrationen, 0,3 bis 0,4 Prozent Kochsalz enthält.

Ich gebe den Auszug aus einem Protokolle einer Beobachtung mit 0,4 proz. Kochsalzlösung.

1,10 sind alle Leukozyten kugelig, die Granula recht ausgeprägt, ihr Gischt ausserordentlich lebhaft und die Kerne als dunkle, zumeist ovale oder bisquitförmige Flecken. 2,35 haftet die übergrosse Zahl der Eiterkörperchen am Glase. Sie sind alle kreisrund, kuchenartig ausgebreitet und daher sind die Durchmesser recht gross. Äusserst zahlreiche, aber kurze, etwa $6 \mu$ lange Trichopoden strahlen nach allen Seiten (siehe Fig. 7). Besonders auffallend ist, dass die Zellkerne durchwegs rundlich oder oval oder bisquitförmig bleiben, nie viellappig sind und dadurch 
den Kernen von Epithelzellen ăhnlich werden. 9 heften sich die Zellen immer mehr ans Glas, breiten sich dabei immer stärker aus, wodurch ihre Durchmaße erstaunlich gross werden. 11,14 sind die Trichopoden an sehr vielen Zellen entwickelt, sie bleiben aber kurz und sind manchmal so zahlreich, dass sie sich am Zellsaum durchkreuzen und um die Zelle ein Gespinst zu bilden scheinen. Die Haare bewegen sich hin und her, als ob sie mit einem Kugelgelenk an die Zelle gefügt wären. Dadurch werden die Trichopoden Flimmerhaaren ähnlich. 17 werden die Trichopoden spärlicher, die Zellen womöglich noch flacher und gleichzeitig deformiert. Die Deformation äusserst sich darin, dass an den Zellen Pseudopodien und Höfe auftreten, die sich dunkel ansehen und in denen der Gischt weiterwirbelt. 20,25 greift die Deformität immer weiter; die Beobachtung wird abgebrochen.

Wichtige Begebenheiten konnte ich nach Zusatz einer 0,5 proz. Kochsalzlösung notieren. 10 fand ich nämlich die Trichopoden sehr schön und recht allgemein ausgebildet, den Gischt ïberall lebhaftest. In der Mehrzahl der Versuche pflegen sich die Zellen an den Objektträger zu heften. Das ist für die Dunkelfeldbeobachtung insofern von Vorteil, als Eiterkörper, die sich an das Deckglas heften, störende Lichtzerstreuungskreise bilden. Um die genannte Zeit fand ich eine Zelle an der Unterseite des Deckgláschens haften. Von ihr strahlte ein starres Trichopodenbüschel in den Kapillarraum gegen den Objektträger $\mathrm{zu}$.

Diese Tatsache scheint mir deswegen so mitteilenswert, weil unter den vielen Möglichkeiten, die das Auftreten von Trichopoden erklären könnten, auch folgende auftaucht. Die Büschel sind nicht selten am Nachhutende der wandernden Zellen anzutreffen. Deshalb leiteten viele, denen ich meine Prăparate zeigte, die Meinung ab, die Trichopoden seien einfach Plasmareste der Wanderzellen und deuteten den Weg an, den die Zellen genommen. Diese Erklärung war natürlich angesichts des frei in die Flüssigkeit hinausstrahlenden Trichopodenbüschels unhaltbar.

Wie leicht man geneigt sein könnte, die Trichopoden als Wegspuren auszulegen, zeigt folgende Episode aus einer Beobachtung mit 0,6 proz. NaCl-Lösung. 12,25 fand ich einen Leukozyt mit ungefäbr 14 am Nachhutende über den Objektträger hin aus- 
strahlenden büschelartigen Trichopoden. Einzelne der Trichopoden sind dichotomisch verteilt. Ihre Länge etwa sechsmal so gross als der dazugehörige Leukozyt im Durchmaße betrug. Die Zelle kriecht wahrend der Beobachtung - es ist mittlerweile 14 geworden - lebhaft nach links oben. Die Trichopoden reichen nach links unten, als ob die Zelle aus dieser Richtung gekommen wäre. Die Umgrenzung der Zelle am Vorbutende wechselt so rasch, dass ich mit der Skizze nicht nachfolgen kann. Das Bild gibt daber eine Kombination der Ansichten, die ich von 12,25 bis 17 hatte. Der Gischt war im Vorhutende besonders lebhaft und ein Teil des viellappigen Kernes erschien im Gischt als dunkler Fleck.

Eine andere Episode diktierte ich 29,15. Damals beobachtete ich schon ungeführ anderthalb Minuten einen Leukozyten, der von rechts oben nach links unten gewandert war, jetzt aber genau von rechts nach links. Zuerst hatte ein Trichopodenbüschel am Nachhutende von rechts obenher bestanden; zuletzt von rechts. Aber auch von der nach links strebenden Vorbutmasse strahlten 29,15 kurze und lebhaft bewegte Trichopoden ins Dunkle

33,15 diktierte ich: Trichopodenbildung ist allgemein geworden; an der übergrossen Mehrzahl der Leukozyten strahlen ganze Büschel aus.

Nach Zusatz einer 0,8 proz. NaCl-Lösung finde ich 3,10 die ersten Trichopoden am Nachbutende eines Leukozyten wie Kristallnadeln anschiessen.

Steigt man mit der Konzentration, so überschreitet man mit ungefahr 0,9 Prozent $\mathrm{NaCl}$ das Optimum für das Phänomen des Gischtes.

In 1 proz. Kochsalzlösung sind die Leukozyten anfänglich eckige Schollen, leuchtendweiss bis an den Rand. Die Kerne unsichtbar; kein Gischt. Aber schon 1,55 erscheint das gewöhnliche Bild mit dem Gischt, der platten Ausbreitung, dem viellappigen Kern. Nur erscheint um die Gischtmasse ein dunkler Hofsaum, kenntlich an einem etwas heller leuchtenden Grenzsaum. Der Kontur dieses Saumes wechselt und wölbt sich manchmal vor, als ob die Zelle einen Pseudopod ausstrecken wollte.

Im grossen ganzen ist bei höheren Konzentrationen die Neigung der Zellen haften $z u$ bleiben geringer geworden, ebenso ist die Trichopodenbildung spärlicher. 
Ich untersuchte noch Konzentrationen von 1,1, 1,2, 1,3, 1,4 und 1,5 Prozent. In letzterer Konzentration hatte ich eine bemerkenswerte Beobachtung, die sechs Minuten, von 2 bis 8 dauerte (siehe Fig. 9, 1 bis einschliesslich 5). Ein Trichopod von schätzungsweise $20 \mu$ strablte 2 ziemlich dick von dem unteren Ende eines Leukozyten nach unten. Die Zelle selbst war weiss glänzend und lag frei und ruhig in der Flüssigkeit. Kein Gischt, kein Kern. 2,45 schwoll die Basis des Trichopoden ampullenförmig an (Fig. 9, 2). Bald darauf, 4, verschwand die Anschwellung und die Zelle wölbt sich nach rechts oben etwas vor, indes der Trichopod ohne ampullenförmige Anschwellung an seiner Basis nach unten vorgestreckt blieb. Kein Gischt, kein Kern, die Zelle hellweiss bis an den Rand. 7 erscheint die Ampulle wieder. 7,45 biegt sich der Trichopod an seiner Wurzel nach links ab. Ich konnte eben noch, 8, die Skizze vollenden, da erlosch mir das Licht; ich musste auf ein Weiterstudium dieser Zelle verzichten. 14 hatte ich das Licht wieder in Stand gesetzt und die Beobachtung aufgenommen. Die Zellen sind mittlerweile flach ans Glas geheftet, der Gischt lebhaftest, die Kerne viellappig. 14,30 brach ich die Beobachtung ab.

Ich stieg bei diesen Versuchen bis zu einer 3,75 proz. Kochsalzlösung und kann nur sagen, dass jede Lösung interessante Bilder lieferte. Die niederen wegen des lebhaften Gischtes, wegen der Kernbilder, die mittleren, etwa 0,5 bis 0,8 , wegen des raschen Auftretens der Trichopoden. Letztere Eigenschaft scheint indessen weniger von den Konzentrationen abzubängen, als davon, dass nicht $z u$ viel Eiter den Lösungen beigemengt war.

Als Basis für weitere Versuche, bei denen es mir auf den Effekt von Beimengungen ankam, wäblte ich 0,75 proz. Lösungen.

\section{B. Versuche mit Traubenzuckerlösungen.}

Ganz ahnliche Versuche mit verschiedenen Konzentrationen schienen mir aussichtsreich, wenn ich Traubenzucker verwendete.

Zunächst griff ich zu einer hochprozentigen Lösung von ungefähr 7 Prozent.

1 sind die weissen Blutzellen kugelig, sie flottieren in der mässigen Strömung des Präparates. Die Granula aestuantia sind unbeweglich. 2 bilden sich um den weissen, die Hauptmasse der Granula einschliessenden Zellteil vakuolenartige, durchsichtige 
Höfe (siehe Fig. 10). Die Zellen selbst heften sich ans Glas, wodurch die Durchmaße grösser werden. 3 sind an einzelnen Leukozyten die Granula in Bewegung zu sehen; die Bewegung ist aber sehr zahm. 8,30 z. B. ist an der vorerwahnten und abgebildeten Zelle (Fig. 10) die Masse der ganz schwach sich bewegenden Granula an einen Zellteil zusammengedrangt (in der Zeichnung schraftiert). An dem dem Zellinneren zugekehrten Teile der Masse liegen drei dunklere Flecke, die offenkundig als der viellappige Kern zu deuten sind. Hieran anschliessend der breite vakuolenartige Hof.

12 finde ich an einem weiteren Leukozyten (siehe Fig. 11) die Masse der schwach sprudelnden Granula an einen Pol der Zelle gerückt. Ihm anschliessend strahlt eine geringe Zahl von Trichopoden aus, von denen einer seitlich einen Zweig angesetzt hatte. Die Zelle selbst ist unbeweglich. Ihren übrigen Raum nimmt eine durchscheinende klare Substanz ein, in welcher ein weiteres, unregelmässig umrahmtes eiförmiges Gebilde, offenbar der Kern auffallt. In den Trichopoden loht es. Das heisst, einzelne Stellen der Faden werden an kurzen Strecken dicker und heller. 19 sind an schätzungsweise j Prozent der Leukozyten Trichopoden entwickelt. Der Gischt der Granula aestuantia ist noch immer sehr trüge und in etwa drei von je zwanzig Zellen erbalten. 21 ist die in Fig. 11 abgebildete Zelle noch immer bewegungslos. Ihre Trichopoden sind verschwunden und das als Kern vermutete Gebilde ist nicht melr zu sehen.

Nun folgt ein interessantes Begebnis.

24 lasse ich durch einen Assistenten am Rande des Deckgläschens vorsichtig gewöhnliches Brunnenwasser zufügen. Dasselbe saugt sich in das Präparat, es entsteht im Gesichtsfelde heftigste Strömung, durch die viele Leukozyten sowie Detritus vorbeigeschwemmt werden. 25 folgt ein zweiter Wassertropfen. Dadurch entstehen im Prăparate Stellen von geringerer Konzentration und wie mit einem Schlage beginnen in allen Zellen ausnahmslos die Granula äusserst lebhaft zu sprudeln; viel heftiger, als es in diesem Präparate je zu sehen war. Die Säume und vakuolenartigen Höfe sind gleichzeitig verschwunden.

Ich muss hervorheben, dass seit etwa 2 oder 3 ein Grossteil der Leukozyten am Objekttrăger oder an der Unterseite des Deckgläschens festhaftet. 
26 hat der Gischt wieder aufgehört, die Säume und Höfe erscheinen wieder, wie sie in den Fig. 10 und 11 abgebildet sind. 28 sind an einigen Leukozyten die mittlerweile verschwundenen Trichopoden wieder erschienen. Das ist nur so zu erklären, dass die Konzentration im Präparate wieder eine höhere geworden ist. 29 lasse ich einen neuen Wassertropfen zusetzen. Neuerdings lebhafte Strömung im Gesichtsfelde. 29,30 verschwinden die Höfe und Säume ein zweites Mal und die Granula aestuantia wirbeln neuerdings allenthalben lebhaftest. 30,40 werden die Säume wieder schwach sichtbar und der Gischt wird träger. 31,30 ein vierter Wassertropfenzusatz; kurz darauf neuerliche Belebung des Sprudelgischtes. 32 nehmen viele Granula gelbe Farbe an. Keine Trichopoden, keine amöboiden Bewegungen. 33,45 beschränlit sich der Gischt abermals nur auf wenige Zellen des jeweiligen Gesichtsfeldes. 35, ein fünfter Wassertropfen wird zugesetzt. Aus vielen Leukozyten rinnen die Granula aus und verlieren sofort beim Verlassen der Zelle ibre Sprudelbewegung. In anderen weissen Blutzellen ist der Gischt zurn Stillstand gekommen. 37 bilden sich an fast allen Eiterkörperchen kugelige, oberfächlich glänende, vakuolenartige Vorwölbungen. Offenbar ist jetzt die Konzentration zu schwach geworden. Ich lasse daher 39 an den Rand des Deckgläschens eine Spur Traubenzuckerpulvers geben. Es entsteht eine Strömung im Gesichtsfelde, die aber sofort stillesteht. 40,30 neuerlicher Zuckerzusatz. 41,30 sind die Eiterkörper alle kugelig, ohne Säume, ohne Gischt. 42 neuerlicher Wassertropfen auf die Stelle, an welche das Zuckerpulver gegeben war. Der Wassertropfen fliesst - das gewöhnliche Ende solcher Versuche - zwischen Deckglas und Linse; der Versuch muss abgebrochen werden.

Das Ausrinnen der Granula ist ein Zeichen grosser Abnahme der Konzentration gewesen, denn bei purem Wasserzusatz ist diese Erscheinung, wie bereits beschrieben, schon nach wenigen Winuten an allen Zellen aufgetreten. Ich hatte also durch diesen Versuch die ganze Skala der Konzentrationen einwirken lassen.

Ich wiederholte aber die Versuche auch getrennt in verschiedenen Konzentrationen und zwar der Reihe nach 0,1, 0,2, $0,3,0,4,0,5$ Prozent. Alle diese Grade sind den lebenden Zellen sehr schädlich. Sie bleiben kugelig, der Gischt ist sehr lebhaft, die Kerne - und das ist wohl sehr sonderbar - sind kugelig 
oder bisquitförmig. Bei ganz niederen Stufen platzen die Zellen rasch, die Granula verlassen die Zellen und der Zellrest ist eine hellweiss glänzende, krümelig aussehende Masse. Bei Konzentrationen von 0,5 Prozent sind noch acht Minuten nach Herstellung des Präparates ziemlich viele, nicht ausgeronnene Leukozyten zu sehen. Bei niederen Konzentrationen, wie z. B. 0,1 Prozent erfüllen die ausgeronnenen Granula das Gesichtsfeld als Detritus, der die Beobachtung recht stört. Trichopoden treten erst bei Graden von 0,4 Prozent auf.

Wenn man mit den Ironzentrationen steigt, so sollte man erwarten, dass auch die Erscheinungen des Auslinnens langsam abnehmen. Diese Erwartung erfüllt sich aber nicht ganz genau und man sieht zuweilen bei Konzentrationen von 0,5 Prozent die Zellen rascher ausrinnen, als bei 0,4 Prozent. Immerhin sind diese Differenzen klein und scheinen davon berzurühren, dass man nicht immer haarscharf gleiche Gewichtsmengen Eiters einem gleichen Quantum der Zusatzflüssigkeit beimengen kann.

Auffallend bleibt hier, wie auch bei entsprechenden Kochsalzlösungen die Gestalt der Kierne. Sie ist bei den gewohnten Sichtbarkeitsverhältnissen so kennzeichnend, dass man die Leukozyten polymorphkernig oder auch „polynukleär“ bezeicbnet. In niederen Konzentrationen sind sie aber $(0,2$ bis 0,4 Prozent) zu einer zentralen Masse zusammengeballt und entweder kugelig oder oval oder bisquitförmig. Ich kann unter Berücksichtigung aller mitlaufenden Erscheinungen diese Formung des Kernes nicht gut als Absterbevorgang gelten lassen.

0,3 Prozent lieferte mir beispielsweise 5,30 ein ähnliches Bild, wie in Fig. 7 dargestellt. Schon bei 0,4 Prozent ist die Mehrzahl der Kerne wieder viellappig.

Bei ebendieser Konzentration sah ich um einzelne der Leukozyten Kranze von sehr kurzen Trichopoden.

Bei einer Konzentration von 0,7 Prozent konnte ich folgende Episode diktieren: 3,55 ist an einem Leukozyten ein Büschel von (gemessen) $16 \mu$ langen Trichopoden $z u$ sehen, von denen 5,10 nur mehr zwei bestehen. Die übrigen sind mittlerweile verschẉunden, ohne dass ich angeben könnte, wie. 5,55 sind auch die letzten zwei Trichopoden verschwunden, einer davon jedoch unter deutlichem, allerdings sehr raschem Kürz̈erwerden. 


\section{Versuche mit Serum.}

Das Serum gewann ich durch Aderlass aus der gestauten Ellbogenvene in eine Zentrifugiereprouvette und sofortiges Zentrifugieren.

Zunäcbst sind 1 die Leukozyten alle hellweiss, kugelig. Der Kern ist noch unsichtbar, wohl aber ist der Gischt ausserordentlich deutlich und lebhaft. Die Zellen flottieren in der Strömung eine Weile, bis sie sich 2 an das Glas, in der Mehrzahl an den Objektträger heften. Sie erscheinen nun grösser, die Kerne werden als dunkle Flecke sichtbar und die Eiterkörper beginnen amöboide Bewegungen auszuführen. 8 begannen an einer Zelle ganz kurze Trichopoden sichtbar zu werden; so kurz, dass ich sie wohl nie bemerkt hätte, wenn ich von ihrer Bildung aus anderen Präparaten nichts gewusst hätte. 12 sehe ich neue Trichopoden, darunter einen von etwa $7 \mu$ Länge. Ein Parallelpräparat zeigt dieselben Veränderungen; es hatte bis zur Einstellung unters Dunkelfeldmikroskop am Tische gelegen.

Andere Serumpräparate verbielten sich analog.

Gewöhnlich tauchten die Trichopoden acht Minuten nach Herstellung des Präparates auf. Es gab aber auch wesentliche Zeitunterschiede. Manchmal waren sie um 14 noch spărlich, ja selbst um 24 noch sehr vereinzelt, das andere Mal waren sie bis 19 spärlich und kurz. Manchmal entstehen sie am Nachhutende kriechender Zellen, manchmal sind sie schon 3 an Zellen zu finden, die sich noch gar nicht festgesetzt haben. Ich fand einmal 16 eine Zelle, von welcher drei Trichopoden der Strömung nach von der Zelle wegflottierten. Andere Male werden die Fäden auch gegen die Stromrichtung vorgestreckt. Es machte mir zuweilen den Eindruck, als ob im Serum Trichopoden schwächer entstünden, bis ich wieder unerwartet Präparate fand, die 15 recht häufige Trichopoden aufwiesen.

Es ist dabei gleichgültig, ob man Eiter des Patienten A mit seinem eigenen Serum nder mit dem Serum eines Patienten $B$ vermengt. Das eine aber schien mir zuverlässig, dass Trichopoden häufiger entstünden, wenn man wenig Eiter zur Herstellung der Präparate verwendet hatte.

Der Gischt und die Polymorphie der Kerne waren aber bei allen Serumpråparaten gleich gut ausgebildet. 
Wenn man das angefertigte Präparat sebr rasch unter das Mikroskop hatte bringen können, so kann es - und das gilt nicht nur für den Zusatz mit Serum allein - gelingen, in den ersten Selkunden Leukozyten zu überraschen, die sich noch lange nicht dazu schicken, sich festzusetzen und an denen noch Trichopodenreste anbăngen, die aber rasch verloren gehen. Es muss erst neuerlich $\mathrm{zu}$ einer Art Gewöhnung an das umgebende Medium kommen, ehe neuerlicbe Trichopoden sichtbar werden.

Ich suchte nun die Serum- und Kochsalzwirkung zu kombinieren, indem ich das Serum bis zur Süttigung salzte. Höher konzentrierte Kochsalzlösungen bewirkten ein Scholligbleiben der Leukozyten. Der Gischt fehlt, kann aber, wie ich das bei der starken Zuckerlösung beschrieb, durch Verdünnungen geweckt werden. Es sind sohin die weissen Blutzellen in hochkonzentrierten Flüssigkeiten gleichsam gelămt. Dasselbe beobachtete man auch in dem gesalzenen Serum. 1,30 waren die Leukozyten kleine Körperchen mit ecligen Umrissen. Sie flottierten im Strome. Granula sind weder als Einzelgebilde zu unterscheiden, noch ist die Spur eines Gischtes wahrzunehmen. 2,45 finde ich an einzelnen spärliche Trichopoden. Dieselben strahlen aber nicht bolzengerade in die Umgebung, sondern hangen schlängelnd als weisse fadige Fortsaltze, wie Algenfädenmassen in einem ruhigen Bache (siehe Fig. 12, skizziert 3,25). 8 traf ich gesichtsfelderweise alle Zellen mit flottierenden Trichopoden. Sie hatten sich im gesalzenen Serum vermehrt.

\section{Versuche mit Zusätzen zur Kochsalzlösung.}

Zehn Eprouvetten mit je zwei Kubikzentimeter einer 0,75 proz. Kochsalzlösung werden mit 1 , beziehentlich 2,3 etc. bis 10 Tropfen 95 proz. Äthylalkohols gemischt. Von diesen Mischungen werden in der angezeigten Weise Präparate hergestellt.

1. Ein Tropfen Alkobolzusatz. 1,10 sind die Zellen alle ans Glas geheftet und entwickeln dunkle, hofartige Säume, die sich vom zentralen, lebhaften Gischt scharf abheben. 3,05 sind die Kerne überall als viellappige Gebilde zu seben. Die Zellen sind kuchenartig ausgebreitet. 3,45 sind die Granula, die in die vorgeschobenen Höfe hineinsprudeln, auffallend gold- bis orangegelb. 4,55 hat eine Zelle (siehe Fig. 13), deren Zentrum von 
einem lebhaft sprudelnden Gischtballen eingenommen ist und deren Kern nicht unterschieden werden kann, einen breiten, hofartigen Saum. Von dem Saume strahlen ringsum zahlreiche kurze Trichopoden, die sich hin- und herbewegen, wie Haare im Winde. 14,50 wird die Zahl von analogen Zellen immer häufiger. 16,35 ist es noch immer nicht zur Bildung der langen, spiessigen Trichopoden gekommen.

2. Zwei Tropfen Alkoholzusatz. Eine spezifische Alkoholwirkung ist mit Ausnahme des Auftretens von hofumsäumten Zellen bis 21,0 j nicht $z u$ sehen. Obschon ich das Präparat mit Eiter aus derselben Quelle wie beim vorhin beschriebenen Versuche gemacht batte, traten ab 6,15 diesmal enorm lange, singuläre oder büschelartige Trichopoden auf. Dieselben werden exakt gemessen und ergeben die erstaunliche länge von $62,46,82$, ja sogar $100 \mu$ !

3. Die erste Spur einer Alkoholwirlkung erscheint erst bei Zusatz von acht Tropfen. Das ist schon eine bedeutende Menge. die bereits das Konzentrationsverhaltnis beeinträchtigt. Erfahrungen an den Kochsalz- oder Traubenzuckerlösungen niederer Konzentrationen bewahren aber vor Verkennungen der Alkoholwirkung, abgesehen davon, dass die Leukozyten in breiten Konzentrationsgraden - etwa 0,5 bis 1 Prozent - bei Zuckeroder Kochsalzlösungen ziemlich gleichmässiges Verhalten zeigen.

Wenn ich von der Hof bildung absehe, die entschieden dem Alkohol zugeschrieben werden muss, so sind als besondere Wirkungen 15 Minuten nach Zusatz von acht Tropfen Alkohol zu notieren gewesen: Im Gegensatze zu schwächeren alkoholischen Mischungen fallt auf, dass man so spät (15 Minuten) noch immer fast kreisrunde, allerdings flach und kuchenartig ausgebreitete Leukozyten findet. Ihr Gischt ist lebhaft, als ob kein Alkohol zugesetzt gewesen wäre. Trichopodenbildung ist behindert Während in reiner 0,75 proz. Kochsalzlösung um diese Zeit die Eiterkörperchen infolge der amöboiden Beweglichkeit schon die bizarrsten Formen angenommen haben, sind hier vereinzelte Leukozyten zu treffen, die sich nicht mehr amöboid fortbewegen. Ihr Grenzsaum ist in seinen Konturen wechselnd, als ob es jetzt und jetzt zu amöboiden Fortsätzen kommen müsste. Es bleibt aber bei diesen Konturänderungen, ohne dass die Zelle sich weiterbewegte. Noch deutlicher wurden diese Erscheinungen der lebhaften InnenArchiv 1. mikr. Anat. Bd. 80. Abt. I. 
bewegung ohne Weiterbewegung der ganzen Zelle nach Zusatz von 10 'Tropfen Äthylalkohol. In letzterer Konzentration breiten sich die weissen Blutzellen nicht einmal mehr der Fläche nach aus. Ihr optischer Durchmesser bleibt deshalb klein und maß höchstens $10 \mu$, aber der Gischt ist ungemein lebhaft, reicht bis an die Grenze der Zelle und der Kontur der Grenzlinie ist beständig wogend und wechselnd. Man hat den Eindruck, dass man die Umgebungsflüssigkeit nur günstiger zu gestalten brauchte und die Zellen würden sich ausbreiten und amöboid kriechen. Bis 5,55 sab ich bei letzterer Zusatzmenge (10 Tropfen) auch Trichopoden. Anfangs kurze und um 5, $24 \mu$ langen, der von einer festsitzenden und lebhaften Gischt zeigenden Zelle aus, der Strömung entsprechend, flottierte.

Es sei bemerkt, dass der optische Durchmesser in 0,75 proz. Kochsalzlösung ausgebreiteter Leukozyten $20 \mu$ und weniger betrug.

Bei einem Versuche mengte ich einer 0,6 proz. Kochsalzlösung eine 0,25 proz. Zyankalilösung bei, ohne dass ich die Zellen in irgendeiner Beziehung Schaden nehmen sah. Da nun auch so starke Alkoholzusätze dem Leben der Leukozyten kein Ende setzen und nur geringe Bewegungseinschränkungen veranlassen, so vermutete ich Ähnliches für andere Zusätze, zunächst Salzsäure.

Das erwies sich aber als irrig. Ich durfte nur ganz geringe Spuren der Säure zusetzen, wenn ich die Leukozyten noch einige nennbare Zeit lebensfähig beobachten wollte. Ein einziger Tropfen einer 2,5 proz. Lösung von Acid. bydrochlor. conc. pur. der österr. Pharmakopoe zu zwei Kubikzentimeter einer 0,75 proz. Kochsalzlösung macht 7,50 eine grosse Reihe von Leukozyten unbeweglich. Ibr optischer Durchmesser ist kurz und der Gischt erloschen. Sieben Tropfen Zusatz verursachen schon nach 5 Minuten ein Erlöschen des anfänglich lebhaften Gischtes und ein Verschwinden allfällig sichtbar gewesener Trichopoden.

Ich griff daher zu einer einprozentigen Lösung von Acid. bydrochl. conc. purum der Pharmakopoe und fügte hiervon 1, 2 etc. Tropfen zu je zwei Kubikzentimeter einer 0,75 proz. Kochsalzlösung.

Der Zusatz von einem Tropfen farbte mein Lackmuspapier noch nicht und bis 19 gab die Beobachtung keinerlei Unterschied der reinen Kochsalzlösung gegenüber.

Wohl aber machen sich schon bei zwei Tropfen deutliche Einflüsse geltend. Bis etwa 8 Minuten ist das Bild das ge- 
wöhnliche. Das heisst, die Leukozyten setzen sich allmählich fest, zeigen lebhaftesten Gischt und kurze Trichopoden. Bald darnach, 8,30, beginnt das Bestreben der Zellen, sich flach auszubreiten, zu erlahmen. Noch ist die Trichopodenbildung nicht eingeschränkt und strahlenförmige Büschel sind recht häufig. Von nun ab begegnet man aber immer häufiger Zellen, die, ähnlich wie beim Alkoholzusatz, rundlich sind und an Ort und Stelle bleiben. Ihr Gischt ist bis an den Zellrand lebhaftest und der Kern ist $z u$ einer zentralen einheitlichen Masse $z u-$ sammengeballt. Am Rande des Leukozyten schieben sich da und dort schwache Andeutungen von Ausbuchtungen oder Einkerbungen vor und zurück, aber nie erscheint ein energisch vorgeschobener Pseudopod (siehe Fig. 14, skizziert 15 bis 15,30). An solchen Zellen fehlen die Trichopoden. Derartige Formen finden sich gesichtsfelderweise, während wieder andere Felder ein ganz normales Verhalten darbieten, das heisst bis 17,38 bizarrste Formen mit Trichopodenstrahlen. Offenbar sind durch die Mengung mit dem Eitersafte kleinere oder grössere Bezirke entstanden, in denen die Flüssigkeiten nicht vollkommen durchmischt sind, in denen daher gar keine oder nur allzu geringe Salzsäuremengen zur Wirkung kommen.

Anders bei drei Tropfen. Schon 1,30 stösst man auf Zellen mit erloschenem Gischt. Er stirbt langsam und allmählich ab. 8 sind Trichopoden nur ganz ausnahmsweise zu entdecken. 11,13 überwiegt stellenweise die Zahl der Zellen mit erloschenem Gischt. Sie sind dann blendend weiss, vollkommen ruhig, der Zellinhalt krümelig koaguliert und die Granula ebensowenig zu erkennen als die Zellkerne. 15,33 beginnen sich an ihnen dunkle Blasen vorzuwölben, deren Vorhandensein nur durch ihre zart beleuchtete Grenzlinie verraten wird (siehe Fig. 15).

An einer einzigen Stelle dieses Präparates, ganz am Rande des Deckglases, entdeckte ich ein sonderbares Bild. Es betraf eine Gruppe von etwa 20 bis 25 Leukozyten, deren Inneres schon krümelig koaguliert war, an denen sich bereits Blasen vorgewölbt hatten und deren Gicht selbstredend längst erloschen war. Von der Peripherie dieser abgestorbenen Eiterzellen hing nun eine erkleckliche Anzahl dicker bandförmiger Trichopoden weg und flottierte in 'der Strömungsrichtung. An manchen waren die Trichopoden etwa 5-6 $\mu$ dick und recht zahlreich, so dass sie buch- 
stäblich Medusenhäuptern glichen. Eine darunter (siehe Fig. 16) hatte einen besonders langen flottierenden Trichopod, der $86 \mu$ mass. Die Beobachtung dieses Prăparates wurde 25,15 abgebrochen. Ich hätte diese Beobachtung nicht mitgeteilt, wenn es mir nicht darauf ankäme, zweifellose Absterbe- und Zelleichbilder zu gewinnen. Denn nur so liess sich entscheiden, ob die Trichopoden, obschon ich an ibnen eindeutige Lebensvorgänge gesehen hatte, nicht etwa Erscheinungen absterbender Leukozyten seien.

Diese Zellen waren in der Salzsäure abgestorben, nachdem sich an ihnen die Trichopoden entwickelt hatten.

Noch rascher wirken vier 'Iropfen Säurezusatz. Schon 1,20 ist der Gischt in vielen Zellen erloschen. 6-8 treiben die Leichen Blasen aus und wenn auch noch 11,34 ein schwacher Gischt ab und zu zu sehen war, so geschah es ausnahmsweise und entsprach wohl sicher einer schleussigen Durchmischung des Eiters mit der Zusatzflüssigkeit.

Ähnlich rasch starben die Leukozyten in Natronlauge. Wieder fügte ich zu mehreren Portionen von je zwei Kubikzentimeter 0,75 proz. Na Cl-Lösung 1,2, 3 etc. 'Tropfen einer 1 proz. Lösung von Natriumbydroxyd.

Die Verdünnung mit einem Tropfen färbte mein Lackmuspapier noch nicht. In ibr verbielten sich die Leukozyten wie in zusatzloser Kochsalzlösung: Sie beginnen sich bald kuchenartig auszubreiten und amöboid $7 u$ bewegen. 8,20 sah ich kurze Trichopoden. Bis 18,03 ereignete sich nichts ungewöhnliches, höchstens, dass ausserst wenig Trichopoden entwickelt waren.

Bei Zusatz von zwei Tropfen - die Flüssigkeit färbte mein Lackmuspapier leicht blau - sind 9,28 die Zellen noch immer kugelig und zeigen wenig Tendenz, zu haften. Der Gischt ist lebhaftest und die Kerne viellappig. Ǔm diese Zeit beginnen aus manchen Leukozyten die Granula auszurinnen, wie beim Aufenthalt in destilliertem Wasser.

Weitere Versuche mit Natronlauge und ihre Wiederholungen brachten keine Aufschlüsse und keine interessanten. weiteren Details, so dass ich es bei dem Mitgeteilten bewenden lasse.

\section{E. Die Leukozyten im Schleim und im Blute.}

Ich suchte nach einem Objekte am Menschen, in welchem lebende Leukozyten in einem ihnen gewohnten Umgebungsmedium 
in nicht zu gedrängter Anzahl unter das Dunkelfeldmikroskop zu bringen waren. Und dieses ersah ich in den Ejekten aus dem Atmungstrakte. Durch Schneuzen, besser durch Husten und Räuspern kann wohl jeder Beobachter leicht Schleimmasse fördern, um sie auf den Objekttrăger zu bringen. Er kann Partikelchen aussuchen, in denen die Zellen nicht besonders gedrängt liegen, ja, unter Umständen kann es gelingen, Gesichtsfelder mit nur drei bis acht Zellen zu finden. Zusätze werden dadurch unnötig und es ist einleuchtend, dass die Zellen von ihrer Lebenskraft nicht viel einbüssen können, ob sie noch ein paar Minuten im Körper oder am Objektträger zubringen.

An solchen Präparaten habe ich ungeahnt lange Trichopoden beobachtet. Einen mit einer gemessenen Länge von $150 \mu$ hielt ich für das Grösstmögliche, als ich auf einen von sage dreihundert " gemessener Länge stiess, der sich natürlich durch zwei Gesichtsfelder verfolgen liess. Der ausserordentlichen Absonderlichkeit wegen demonstrierte ich den Faden allen Milkroskopkundigen, deren ich in dem Augenblicke habhaft werden konnte. Der Trichopod ging von einem Schleimkörperchen aus, in welchem der Körnergischt von gewohnter Lebendigkeit war. Die Zelle batte nur diesen einen Fortsatz. Er erstreckte sich in jener Richtung, die durch die faserige Schleimmasse vorgezeichnet war und zog leicht gebogen dahin. Ich mass ihn mehrere Male, weil es schwer war, an dem durch zwei Gesichtsfelder ziehenden Faden das Maß des Okularmikrometers an der richtigen Stelle wieder anzusetzen. Wahrend des Verschiebens riss er etwa $50, k$ vom Zellansatz ab. Das freie Ende blieb gestreckt, das an der Zelle hängende Ende flottierte aber schlängelnd. Leider konnte ich das weitere Schicksal der Enden aus ausseren Gründen nicht abwarten.

Der Gischt der Schleimzellen ist bekanntlich auch in durchfallendem Lichte leicht $z u$ sehen.

Ich versuchte die Verhältnisse in den Schleimpräparaten nachzuahmen, indem ich Trippereiter einer Lösung von Mucilago gummi arabici in drei Teilen Wasser zusetzte. Dieser Zusatz erwies sich ungeeignet. Schon nach 8 Minuten ist der Gischt erloschen. Die Zellen bleiben kugelig, zeigen den Gischt anfangs auch in durchfallendem Lichte und es kommt nicht zur Trichopodenbildung. Der Zusatz scheint sehr schädigend zu sein, denn 
an einer Epithelzelle, die zufällig in dem Präparate entbalten war, Iram es zu blasigen Auftreibungen, äbnlich wie bei den Salzsäureversuchen an den Eiterkörperchen. Solche Auftreibungen kommen dann auch an den Leukozyten des Mucilagopräparates zum Vorschein. Gleich zu Anfang der Beobachtung waren schöne Trichopoden und Amöboidfortsätze da, die die Tendenz zeigten, länger zu werden, aber der frühzeitige Tod der Zelle verhinderte die Entwicklung der Erscheinung, gar so, wie sie im Schleim zu sehen war.

Die enorme Länge der Zellfäden im Schleimpräparate hat aber eine gute Erklalrung in folgendem. Die Trichopoden treten nämlich erst längere Zeit nach Anfertigung des Präparates auf. Anfunglich sind die Zellen kugelig oder kreisrund, vielleicht etwas abgeflacht. Sie zeigen keine amöboide Bewegung, wohl aber ein fortwährendes Wechseln des Zellionturs, als ob es jetzt und jetzt zum Vorstrecken eines Amöboidfortsatzes kommen müsste.

Wenn man mit einem Deckglase einen Wassertropfen deckt, so beginnt das physikalische $\mathrm{Phänomen} \mathrm{der} \mathrm{Kapillarwirkung} \mathrm{seine}$ Tätigkeit. In kapillaren Röhrchen steigt das Wasser. Dasselbe geschieht auch zwischen Deckglas und Objektträger. Weil aber ersteres leicht und beweglich ist, so nähert sich das Deckglas passiv dem Objelrttralger. Diese leise Gewalt macht sich auch am Schleimpraparat geltend, um so mebr, als es am Rande eintrocknet. Ich konnte nun verfolgen, dass die Schleimzellen nach einer Weile - offenbar durch den leisen Druck - ihre rundliche Gestalt mit einer birnförmigen vertauschen. Am spitzen Ende entsteht jetzt der Faden, der sich manchmal ans Deckglas anheftet. Nimmt der Druck zu, so glitscht die Zelle zwischen den Schleimmassen von ihrer Anheftung weg und nun spinnt die Zelle den Faden, so lange die Kräfte fortwirken. Der Lănge des Fadens ist sohin kaum mit $300 \mu$ eine Grenze gesetzt. Eine selbständige amöboide Fortbewegung fehlt den Zellen des Schleimes gånzlich.

Die Beobachtungen des nativen Blutes endlich klären am meisten auf, was von all dem Mitgeteilten auf Rechnung der Lebenseigenschaft der weissen Blutzellen zu setzen ist. Man findet, dass die amöboide Beweglichkeit den Zellen mit neutrophilen Granulis ebenso zukommt, wie den Zellen mit basophilen Granulis. Der Gischt wird vor allem von den neutrophilen, dann 
aber auch von den basophilen, nicht aber von den eosinophilen Granulis mitgemacht. Die eosinophilen Granula sind daher keine Granula aestuantia. Dadurch, dass die basophilen Granula viel blasser und durchscheinender aussehen, macht auch ihr Gischt einen matteren Eindruck.

Sowohl die basophilen als die neutrophilen Leukozyten entwickeln im nativen Blutpräparat Trichopoden. Von den eosinophilen Zellen weiss ich diesbezüglich nichts anzugeben.

Ich möchte mir aber gestatten, Nachuntersuchern den Rat zu erteilen, Blutpräparate erst zu studieren, nachdem Eiterpräparate mit $0,7-0,9$ proz. Kochsalzlösungen beobachtet worden waren, weil mich die Erfahrung lehrte, dass Herren, denen ich nur Blutpriparate zeigte, die Trichopoden mit Fibrinfäden verwechseln und geneigt werden, die Erscheinung überhaupt mit der Blutgerinnung in Zusammenhang zu bringen, was nach dem Mitgeteilten selbstredend ausgeschlossen ist. Ich hoffe vielmehr, dass man nach Durchprobung der Zellen in den verschiedenen zugänglichen Medien in Übereinstimmung mit mir die Veränderlichkeit ihrer Kerne, den Gischt und die Trichopodenbildung als Äusserungen des Zellebens ansehen wird.

Es liegt auf der Hand, dass mit den paar hier beschriebenen Versuchen nicht alle Möglichkeiten erschöpft sind, welche uns über das Leben der Leukozyten Aufklärung bringen können. Die Reihe der Säuren kann erweitert werden und es ist gar nicht ausgeschlossen, dass der Chromsäure, die an lebensfrischen menschlichen Epithelzellen so wunderbare Bilder erzeugt oder der Karbolsäure gegenüber spezifische Reaktionen auftreten können. Ebenso kann man die Reihe der Gifte über das Zyankali namentlich auf die Alkaloide ausdebnen. Oder, es bleiben physikalische Einflüsse, wie elektrische Entladungen, Radiumstrahlen zu studieren. Kurz, ich bin mir nur zu sehr bewusst, von dem Probleme kaum mebr als einen ganz kleinen Teil gelöst zu haben.

Innsbruck, am 21. Mai 1912. 


\section{Erklärung der Abbildungen auf Tafel XXV.}

Die Zeichnungen machen nur den Anspruch rasch hingeworfener Skizzen, denn das Material, lebende Leukozyten, veränderte zu rasch das Aussehen. Eine Zeichenkamera wurde nicht verwendet. Immerhin habe ich mir die grösste Mühe gegeben, die Grössenverhältnisse getreu nachzuahmen. Gezeichnet wurde bei Dunkelfeldbeleuchtung, Kompensationsokular 4 und Objektiv 9 $R$ e i c h e r t, Tubuslänge $160 \mathrm{~mm}$.

Fig. 1. Eiterzelle in 0,75 proz. Kochsalzlösung a 10, b 12,30, c 15, d 17 Min. nach Vermengung des Eiters mit der Kochsalzlöșung. f, ein bei gleicher Vergrösserung gezeichneter Erythrozyt, zum Vergleich der Mabe. a, die Zelle ist bis an den Rand rom Körnergischt erfüllt. Die Körner sind nicht eingezeichnet. Der Kern ist vierlappig. $b$, der Körnergischt ist schraffiert. Am oberen Pol hat die Zelle eine durchsichtige Substanz entwickelt. Der Kern ist dreilappig geworden. Die Zelle hat sich am Glase ausgebreitet, weshalb ihre Durchmabe grösser wurden. c, dieselbe Zelle einige Minuten später. Die durchsichtige Substanz ist verschwunden, der Gisclit reicht bis an den Zellrand, der Kern ist dreilappig. d, die Zelle ist noch mehr ausgebreitet, der Gischt, schraffiert, erfüllt einen Teil der Zelle, der übrige ist vom dreilappigen Kern erfüllt.

Fig. 2. Andere Eiterzelle in gleicher Umgebung, 28 Min. nach Herstellung des Präparates. Nach links oben strahlen die Trichopoden in Form eines dichten Büschels. Der Körnergischt, schraffiert, erfüllt einen Teil der Zelle. Ihm anliegend der Kern. Die übrige Substanz ist durchsichtig.

Fig. 3. Andere Eiterzelle in gleichem Medium. Nach oben Trichopodenbüschel, einige Trichopoden gegen das Ende dichotomisch. Der Gischt der Granula aestuantia ist schraffiert. 31 Min. nach Herstellung des Präparates.

Fig. 4. Andere Eiterzelle unter denselben Bedingungen. 34 Min. nach Herstellung des Präparates. Zn Beginn der Skizzierung bestand ein Trichopod nach links oben, der fünfmal so lang war als das Durchmal3 der Zelle. Der Trichopod verschwand, dafür tauchten während der Skizzierung die zwei Trichopoden rechts und oben auf. Lebhafter Gischt, schraffiert. Vierlappiger Kern. Zwischen Gischt und Zellrand stellenweise durchsichtige Substanz.

Fig. 5. Zelle in 3,7á proz. Kochsalzlösung $16^{z} / 4$ Min. nach Herstellung des Präparates, mit Trichopod. Derselbe haftet bei $x$ am Glase. Die Strömung im Präparate lässt den Leukozyten nach rechts unten baumeln. Vorbeigetriebene Eiterzellen schwenken den Leukozyten an der zellulären Insertion des Trichopoden hin und her. Die Zelle hatte sich nicht ausgebreitet, blieb schollig und weiss. Gischt fehlte. Kern unsichtbar. Beobachtungsdauer $7: 4 \mathrm{Min}$. 
Fig. 6. Leukozyt unter denselben Verhältnissen, 28 Min. nach Herstellung des Präparates. Er haftete mit einem Pseudopod bei $x$ am Glase, indes der Trichopod in der Richtung der Strömung nach rechts unten flottierte.

Fig. 7. Eiterzelle in 0,4 proz. Kochsalzlösung 2 Min. 35 Sek. $(2,35)$ nach Herstellung des Präparates. Stark abgeflacbte, kuchenartig ausgebreitete Zelle. Gischt (schraffiert) bis an den Rand der Zelle. Kurze Trichopoden am Zellsaume. Bisquitförmig gewordener Kerm.

Fig. 8. Leukozyt in 0,6 proz. Kochsalzlösung. Beobachtet von 12,25 bis 17 Min. nach Herstellung des Präparates ( $t$ Min. 35 Sek.). In lebhafter Wanderung begriffen. Bizarre Form. Reiches Trichopodenbüschel am Nachhutende, wie eine Wegspur. Die Zelle wandert nach links oben. Lebhaftester Gischt, schraffiert. Kreisrund gewordener Kern.

Fig. 9. Eiterzelle in 1,5 proz. Kochsalzlösung. Beobachtungsdauer 6 Mlin., von der 2. bis 8. Min. nach Herstellung des Präparates. Stadium I Trichopod nach unten, 2 Min. Stadium II, an der Trichopodenwurzel entsteht eine ampullenartige Ausweitung. Stadium III, 4 Min. nach der Herstellung des Präparates. Die Ampulle ist verschwunden, nach oben rechts wölbt sich pseudopodienartig Zellmasse vor. Stadium IV, 7 Min. Die Ampulle erscheint wieder. Stadium V. Der Trichopod biegt an der zellulären Anheftungsstelle plötzlich und ohne Strömung nach links ab. Die Zelle selbst weiss und schollig; ohne Gischt, ohne sichtbaren Kern.

Fig. 10. Leukozyt in 7 proz. Traubenzuckerlösung, beobachtet 2 bis 9 . Skizziert um 8,30. Schraffiert die Masse der Granula aestuantia, deren Gischt sehr matt war. Daran rechts anschliessend drei kugelige Gebilde, wahrscheinlich der dreilappige Kern. Hieran nach rechts anschliessend durchsichtige Zellsubstanz.

Fig. 11. Leukozyt unter denselben Bedingungen, beobachtet ron der 12. Min. nach Herstellung des Präparates bis zur 21. Min. Anfangs waren die Trichopoden zu sehen wie abgebildet. Rasch verschwanden sie. An der Wurzel der Trichopoden Granulamasse mit mattem Gischt. Daran anschliessend durchsichtiger Zellteil mit elliptischem Gebilde, wie ein Kern. 21 ist aber dieses Gebilde verschwunden.

Fig. 12. Leukozyt in kochsalzgesïttigtem menschlichen Serum 3,25 nach Herstellung des Präparates. Die Zelle ist weiss, schollig, nicht angeheftet. Zwei Trichopoden flottieren von ihr weg. Kein Gischt, kein sichtbarer Kern.

Fig. 13. Eiterzelle in $0,7 \mathfrak{~ p r o z . ~ K o c h s a l z l o ̈ s u n g , ~ z u ~ d e r e n ~ z w e i ~ K u b i k - ~}$ zentimeter ein Tropfen starker Äthylalkohol gegeben war. 4,45 bis 8,50 (beobachtet durch 4 Min. 5 Sek.). Im Zellzentrum die Masse der Granula aestuantia mit lebhaftem Gischt. Kein Zellkern sichtbar. Ringsum durchsichtige Zellsubstanz mit Trichopodensaum. Die Trichopoden bewegen sich wie Haare im Winde. 
586 Ludwig Merk: Über die Trichopoden und Granula etc.

Fig. 14. Eiterzelle in 0,75 proz. Kochsalzlösung, zu deren zwei Kubikzentimeter zwei Tropfen einer 1 proz. Lösung von Acid. hydrochlor. conc. pur. der österr. Pharmakopoe gefügt waren. 15 Min. nach Herstellung des Präparates. Gischt bis an den Zellrand. Die Zelle versucht amöboide Fortsätze auszustrecken, daher wechselt der Kontur beständig. Es bleibt aber bei kleinen Ausbuchtungen und Einkerbungen. Im Zentrum der massige Kern.

Fig. 15. Tote Zelle. Drei Tropfen Salzsäurezusatz. 15,33 Kr ü meli g koagulierte Zellsubstanz, Gischt erloschen, kein Kern sichtbar. Nach links treibt eine Blase aus.

Fig. 16. Leukozytenleiche unter denselben Bedingungen. Blasige Auftreibung an der toten Zelle nach links oben. Dicke Trichopoden rings an der Zelle. Der längste mass $86 \mu$. 